\title{
Ru-Zr (Ruthenium-Zirconium)
}

\section{H. Okamoto}

The Ru-Zr phase diagram in [Massaalski2] was primarily based on [1988Ere] and the assessment of this system was published later by [19930ka]. Thermodynamic modeling of this system was attempted as described below, all based on the data of [1988Ere]. [1997Mah] first calculated the Ru-Zr phase diagram. Unusual inflection points exist along the liquidus. Probably, thermodynamic parameters were inappropriate. Recently, [2007Idb] and [2008Ran] attempted thermodynamic assessment of the $\mathrm{Ru}-\mathrm{Zr}$ system independently. Their calculated phase diagrams are very similar. Figure 1 shows the more recent work of [2008Ran]. This phase diagram is believed to be a good representation of the experimental data of [1988Ere].

\section{References}

1993Oka: H. Okamoto, The Ru-Zr (Ruthenium-Zirconium) System, J. Phase Equilib., 1993, 14(2), p 225-227

1997Mah: K. Mahdouk, K. Elaissaoui, J. Charles, L. Bouirden, and J.C. Gachon, Calorimetric Study and Optimization of the Ruthenium-Zirconium Phase Diagram, Intermetallics, 1997, 5, p 111-116

2007Idb: M. Idbenali, C. Servant, N. Selhaoui, and L. Bouirden, Thermodynamic Assessment of the Ru-Zr Binary System, J. Phase Equilib. Diffus., 2007, 28(3), p 243-249

2008Ran: H. Ran, Z. Du, C. Guo, and C. Li, Thermodynamic Modeling of the Ru-Zr System, J. Alloys Compd., 2008, 464, p 127-132

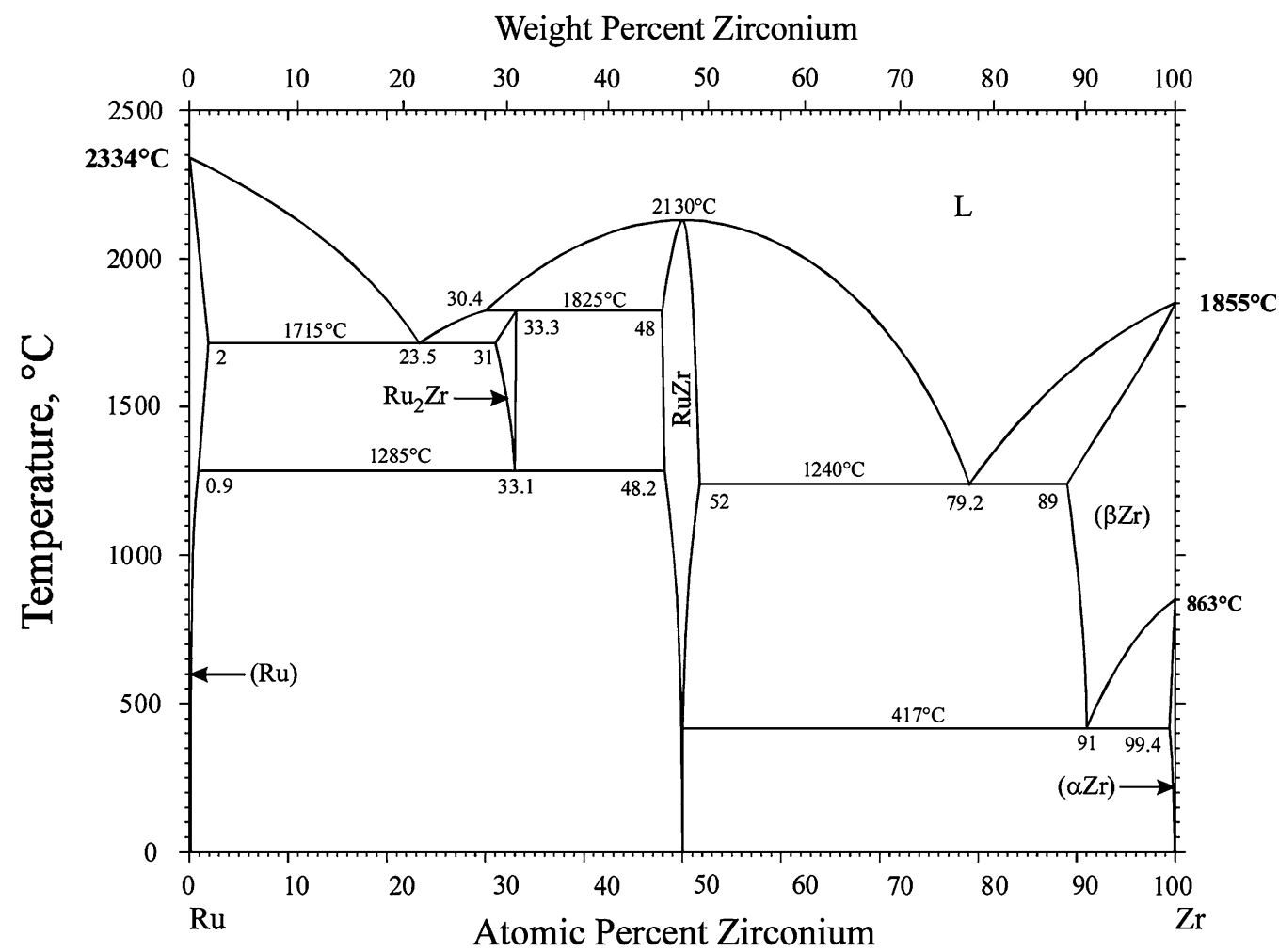

Fig. 1 Ru-Zr phase diagram 